\title{
A concept development of an early warning system for toxic sewage detection
}

\author{
Anna Jurga ${ }^{1, *}$, Natalia Gemza ${ }^{2}$, and Kamil Janiak ${ }^{1,2}$ \\ ${ }^{1}$ Faculty of Environmental Engineering, Wroclaw University of Technology, Poland \\ ${ }^{2}$ Wroclaw Municipal Water and Sewage Company, Poland
}

\begin{abstract}
The article presents a concept of an EWS (early warning system) for toxic sewage detection upstream from Wroclaw Wastewater Treatment Plant. It includes design and construction of three toxicity warning stations, situated in municipal sewage system. Early detection of toxic contaminants provides time for corrective actions. Wastewater toxicity level is based on activated sludge OUR (Oxygen Uptake Rate) measurement. The database of normal level of activated sludge OUR is collected during the measurement initial phase. Hence, if toxic event occurs, device will measure decreased OUR value and WWTP operators will be alarmed. Additionally, flow measurement is carried out. It allows to estimate the volume of a toxic stream. Development of the early warning system requires solving minimum six different scientific and technical issues and is a subject for a complex research project.
\end{abstract}

\section{Introduction}

Activated sludge poisoning by toxic constituents can occur in any wastewater treatment plant and can have catastrophic consequences for the treatment processes [1, 2] Toxic inflow can cause collapse of nitrification process and lead to significantly exceeded total nitrogen concentration in the effluent. Most of the times the inflow of toxic wastewater is noticeable after causing process failure and when it is too late for any corrective actions. Wastewater treatment plant can be equipped with an early warning system. It includes a few toxicity measurement points placed at selected locations of the sewage collection system. The toxic wastewater inflow is detected early enough for WWTP operators to react and introduce the appropriate set of corrective actions. Measurement points locations divide sewage system into main sectors. As a result, it is possible to search for the perpetrator of a toxic discharge effectively. Under normal circumstances, the extent of the sewerage network and a large number of sewage connections is practically impossible to locate toxic discharge.

The construction of an efficient system is a big challenge. Scientists all over the world make individual attempts to build such a system [3, 4]. There are also a number of commercially available devices for determining sewage toxicity. The first scientific challenge is to choose appropriate toxicity assessment method. Subsequent challenges

\footnotetext{
*Corresponding author: anna.jurga@pwr.edu.pl
} 
include localization and calibration of the system in such way that its action would not give false positive and negative results. Aim of this paper is to design conceptual framework of the early warning system for Wroclaw Wastewater Treatment Plant for inhibition event prevention.

\section{The concept of the system}

\subsection{General description of the EWS}

Main components of the system are measurement units located in key points of sewer network. In order to achieve the most satisfying results, their location should provide sufficient time for reaction and minimize number of measurement units. Each measurement unit is composed of toxicity measurement apparatus and flow meter. Data from measuring points is continuously sent to PC where analysis is carried out according to an algorithm described in point 2.3. In case of toxicity detection, information is transferred to wastewater treatment control room as well as to sewer control room, since suggested corrective actions may include both wastewater treatment process and pumping station management.

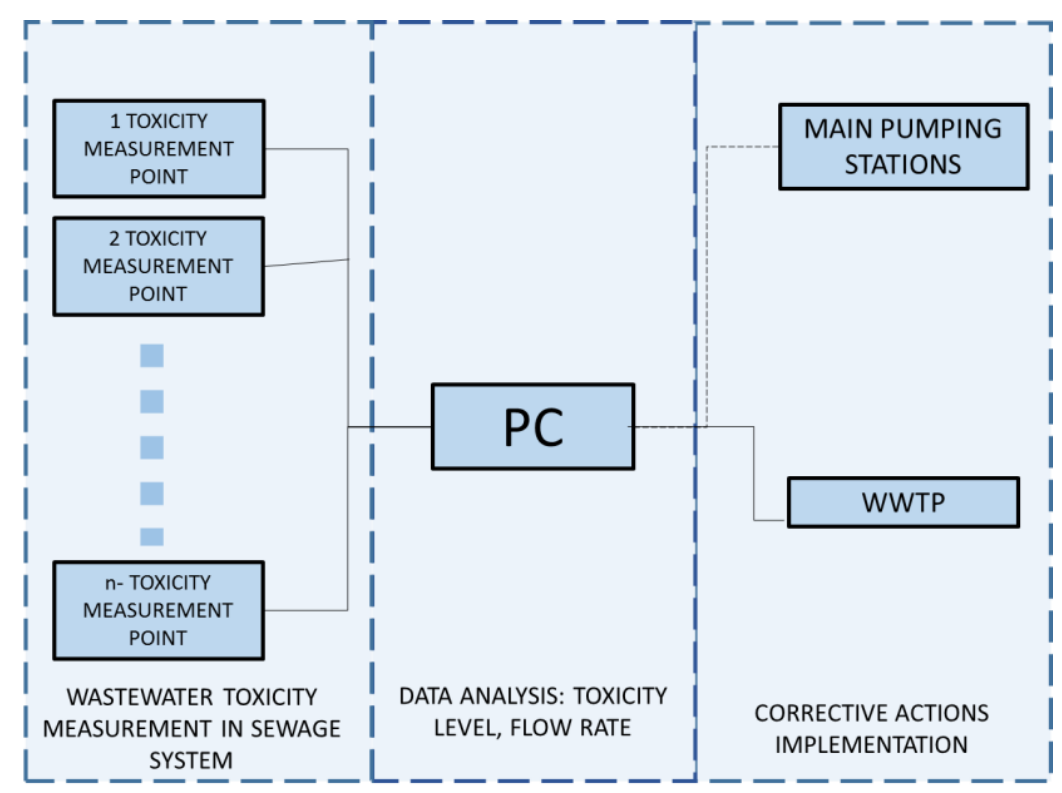

Fig. 1. Block diagram of toxicity warning system.

\subsection{Location of measurement units}

Figure 2. presents proposed locations of measurement units in Wrocław sewer system. In preliminary concept three measurement units are proposed. First one is located in the central part of Wroclaw, near Port Polnoc pumping station. This unit will monitor wastewater from the northern part of city. The second one is also located in the central part of city, near Port Poludnie pumping station. This station will monitor wastewater from the southern part of the city. There is $c a .13 \mathrm{~km}$ between those units and wastewater treatment plant. The third unit will be located at "Sleza" sewer outlet. This unit will monitor wastewater from the remaining part of city. There is circa $6,5 \mathrm{~km}$ from this unit to wastewater treatment plant. 
With average wastewater velocity of $0,6 \mathrm{~m} / \mathrm{s}$, time for reaction will amount between 2,5 and 5,5 hours $(0,5$ hour is required for measurement). As this time is relatively short, the system will be expanded in the future with new units in further segments of sewer. More measurement units will allow to divide the sewer system into sectors which will increase chances for finding toxic wastewater sources.

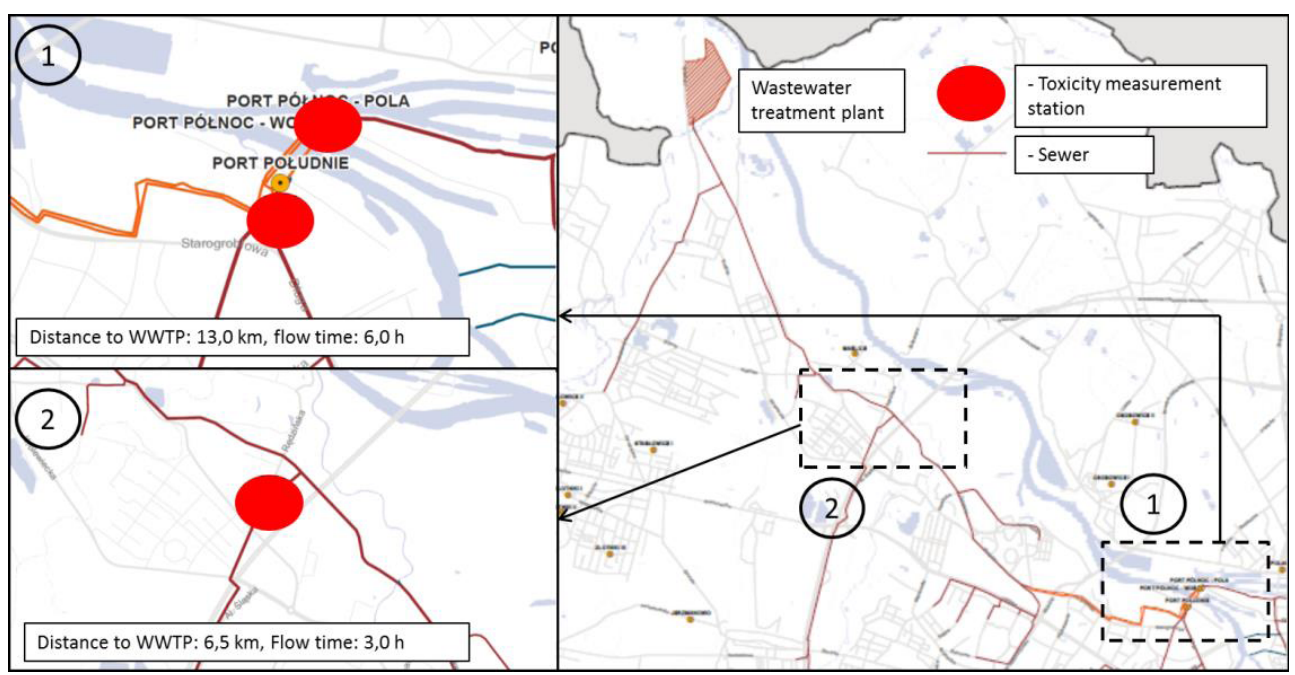

Fig. 2. Location of toxicity measurement points.

\subsection{Measurement method}

Toxicity of wastewater can be measured with many different methods [2, 3, 5-10]. Not every method can be used in toxicity warning system as they do not comply with its requirements which are: short time of response, easy handling, reliability and on-line data registration. In this concept of the system, a respirometric method has been chosen. Principle of this method is easy to understand, respirometric test can be conducted without need of very expensive and complicated equipment. It is also possible to on-line register measurement results. As nitrification inhibition will likely be the first result of toxic wastewater inflow to wastewater treatment plant, direct measurement of oxygen consumption by nitrifiers is a proper way to asses wastewater toxicity [11].

Respirometric measurement is conducted in respirometer. This device is composed of reactor filled with activated sludge, oxygen probe and stirrer. Measurement is conducted in controlled conditions with $\mathrm{pH}$ and temperature kept at given value. In order to carry respirometric measurement, sludge is aerated to oxygen saturation concentration. Afterwards aeration is switched off and sludge starts to use dissolved oxygen. Oxygen concentration changes are registered and converted to oxygen uptake rate. Healthy sludge fed with non-toxic wastewater will have high oxygen uptake rate, while sludge fed with toxic wastewater will have much lower oxygen uptake rate. The difference between those values can be converted into wastewater toxicity degree. Algorithm of an operation is described in point 2.3. Exemplary oxygen curve obtained during respirometric test is presented in Fig. 3. 


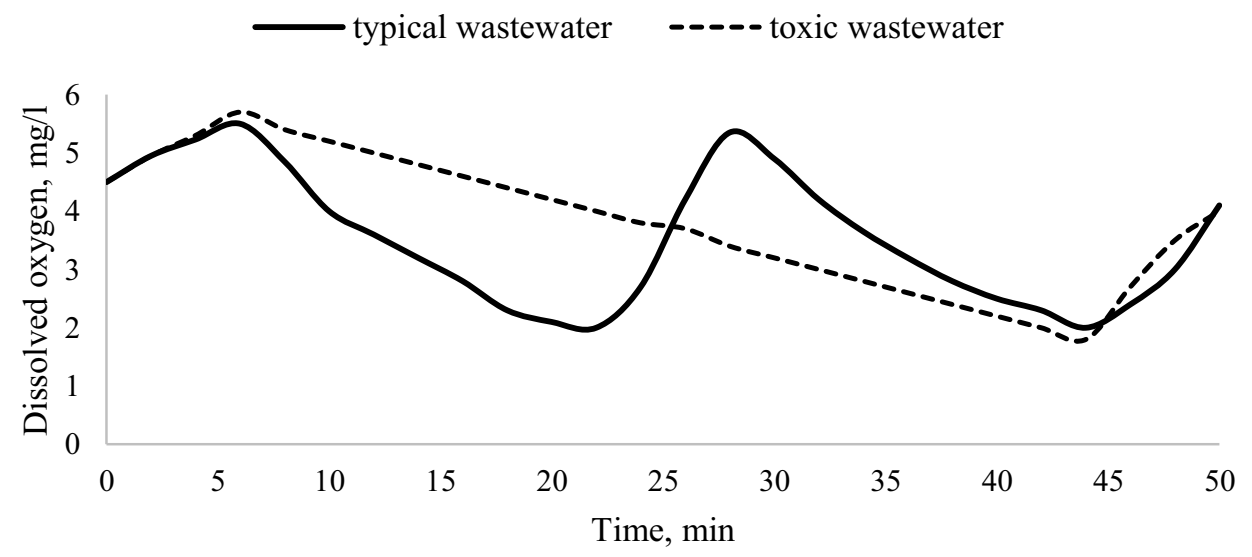

Fig. 3. Oxygen curve during respirometric test.

\subsection{Algorithm of operation}

Algorithm of operation is shown in Fig. 4. Every measurement unit conducts two subsequent respirometric tests every 30 minutes. Reference measurement (1) is used to check whether condition of sludge is not changing in time. In this measurement the sludge is fed with pure substrates such as ammonium salts. If oxygen uptake rate obtained with pure substrate is different than average value of previous measurements, correction coefficient need to be calculated (2) because condition of sludge has changed. For example: if reference value is $20 \%$ lower than the average one, this difference must be included in the analysis of the results obtained from test with wastewater. Without correction, false positive or false negative results may occur as change of sludge condition will be undetected. After reference measurement, one with sewage is conducted (3). Sewage dose is properly selected to ensure that sludge loading in respirometric reactor is the same as in wastewater treatment plant. Oxygen uptake rate from test with sewage is subsequently modified according to results from reference measurement and compared with typical value of oxygen uptake rate of sludge fed with non-toxic wastewater (4) As measurement points are placed on sewer transporting only fraction of WWTP influent volume it is necessary to calculate whether overall stream will be toxic in case of mixing toxic wastewater with nontoxic (5). In case when toxicity of overall stream is expected to be toxic, the red alert is announced. If toxicity of overall stream is not expected, the yellow alert is announced. Red alert should be followed with reaction of wastewater treatment plant crew while the purpose of yellow one is to increase attention. 


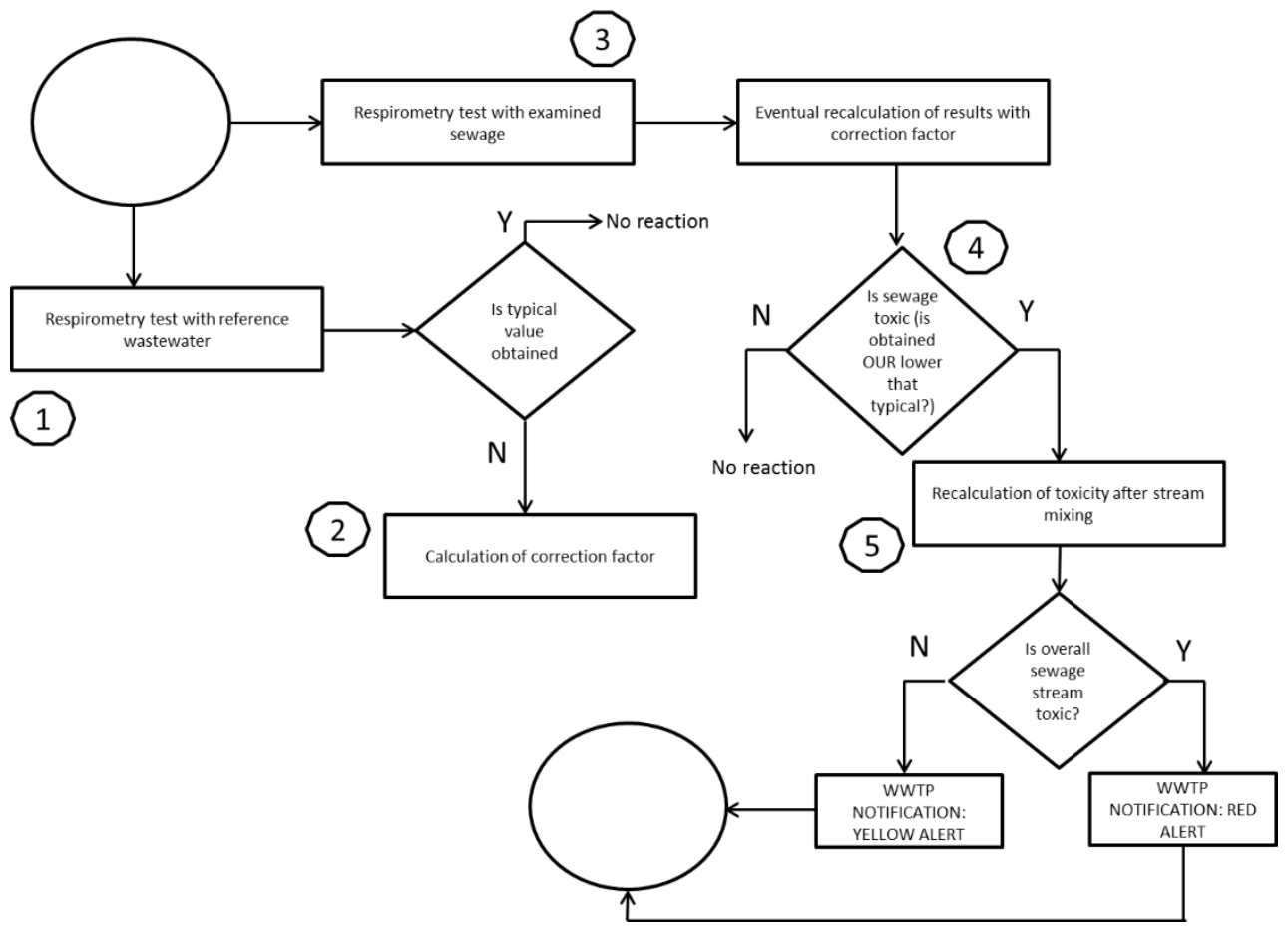

Fig. 4. Algorithm of operation.

\section{Preventive actions after toxicity detection}

Toxic sewage warning is sent to WWTP operators in advance due to right location of measuring points. It gives plant operators time necessary to prepare facility and introduce one of a few proposed preventive actions to minimize consequences of toxic stream entering biological chamber. Applicability of each of proposed preventive actions on a particular WWTP is limited by the specific plant configuration i.e. flow equalization basin or other wastewater storage tank, design and number of treatment lines and receiving body characteristic. Preventive actions accommodated to Wroclaw WWTP setup are as follows:

- $\quad$ lack of any additional flow equalizer ahead from inlet works

- $\quad$ primary settling tanks preceding biological chambers

- $\quad 5$ parallel treatment lines

- $\quad$ effluent discharge into the river.

Preventive actions listed in the table below might be combined and implemented in a variety of configurations. 
Table 1. List of the corrective actions.

\begin{tabular}{|c|c|c|}
\hline No. & Corrective action & Description \\
\hline 1 & $\begin{array}{c}\text { Increasing/Decreasing main pumping } \\
\text { station flow rate }\end{array}$ & $\begin{array}{c}\text { Toxin concentration can be reduced by increasing } \\
\text { sewage flow rate. In case of measuring points located } \\
\text { upstream from pumping station reducing flow rate } \\
\text { allows to dilute toxic compound with inflowing } \\
\text { wastewater. Toxic stream identified downstream from } \\
\text { pumping station requires corresponding action - } \\
\text { increase in sewage pumped volume. }\end{array}$ \\
\hline 2 & Chemically enhanced primary & $\begin{array}{c}\text { Chemical precipitation of heavy metal cations or } \\
\text { sorption of soluble toxic compounds onto settling } \\
\text { primary sludge flocs. }\end{array}$ \\
\hline 3 & $\begin{array}{c}\text { Hydraulically isolating one/a few } \\
\text { treatment lines }\end{array}$ & $\begin{array}{c}\text { A part of plant nitrifying biomass is protected from } \\
\text { toxins casing inhibition which helps with faster } \\
\text { subsequent process start-up. }\end{array}$ \\
\hline 4 & $\begin{array}{c}\text { Aeration shutting down/ reduction, } \\
\text { shutting down agitators }\end{array}$ & $\begin{array}{c}\text { Causing sludge settling helps with preventing toxins } \\
\text { from penetrating easily though all sludge flocs. } \\
\text { Mixing and/or aeration is recovered as soon as toxic } \\
\text { stream leaves treatment line. }\end{array}$ \\
\hline
\end{tabular}

\section{Scientific and technical challenges}

\subsection{Main research goals}

In order to achieve full efficiency of the proposed system, an extensive research is needed. Main research goals are as follows:

a. determination of the number of OUR measurements required for reliable average value estimation,

b. determination of sample collection interval,

c. selection of substrates for reference measurement,

d. selection of reactor's parameters (SRT, $\mathrm{pH}, \mathrm{DO}, \mathrm{T}$ ) in order to ensure that sludge in reactor is identically susceptible to toxic wastewater as activated sludge in wastewater treatment plant,

e. determination of typical oxygen uptake rate of sludge fed with non-toxic wastewater and pure substrates,

f. determination of correction factor of partial stream toxicity to WWTP influent toxicity.

\subsection{How many repetitions of oxygen uptake rate measurement are necessary}

This issue refers to measurements with pure substrate as well as with wastewater. Number of subsequent measurements of oxygen uptake rate is important due to confidence interval of obtained value. If confidence interval is large (small number of repetitions) one cannot be certain about true value of OUR and thus detection threshold is small. From this point of view more repetitions provide more reliable results. As each measurement takes $c a$. 10 minutes, with higher number of repetitions interval between samples gets too long and the system loses its ability of toxic wastewater fast detection. If the required number of repetitions is higher than 5-6 it will be necessary to shorten single measurement by changing aeration procedure. This can be achieved by alteration from aeration with air to artificial aeration with hydrogen peroxide as aeration is the most time consuming process 
during oxygen uptake rate measurement. This modification may change sludge behavior and cannot be implemented without investigation. It is highly possible that at least 3 repetitions of each measurement will be needed.

\subsection{Sample collection interval}

Minimal interval between samples depends on time of measurement and the number of repetitions of measurement. With 10 minutes for each measurement and 3 repetitions with pure substrate and 3 with wastewater, the minimal interval cannot be shorter than 60 minutes It is worth concerning whether interval can be longer without loss of ability for fast detection. Longer interval is beneficial as it lowers maintenance costs.

\subsection{Substrates in reference measurement}

It should be decided whether ammonium salts, organic compounds or mixture of both should be substrates in reference measurement. Nitrification is most sensitive process and its failure will be probably first symptom of sludge poisoning. From this point of view ammonium salts seems to be the most appropriate substrate for reference measurement as certainty that nitrification is stable will be most important for system detection threshold. Other substrates cannot be ruled out with this simple analysis, therefore this issue will be addressed.

\subsection{Selection of parameters of the reactor in the monitoring station}

This is probably the most significant research task. Ensuring the reliability of toxicity test at the monitoring station will require the calibration of operation parameters of reactor. Biomass sensitivity to toxic substances should coincide with the sensitivity of the sludge from WWTP. Otherwise, the system may respond with false results. As a consequence, the operator of WWTP may be exposed to adverse effects, e.g. financial. This task will require exposition of the biomass (from the reactor) and the activated sludge (from treatment plant) to the toxic contaminants. The answer will be examined and adjusted if necessary. Perhaps there is going to be a need for regular seeding reactors sludge from wastewater treatment, to ensure the validity of the test.

\section{6 „Typical" values of the oxygen uptake rate}

Attempts will be taken to precisely determine the typical oxygen uptake rate in the absence of toxic compounds in the wastewater. It should be taken into account that it is possible that factors other than the presence of toxic compound can cause drop in OUR value The adopted value of deviation from the typical parameters will influence the sensitivity of the system, as well as its ability to detect toxic waste. If the system is too sensitive it will cause a large number of false alarms. However, low sensitivity may result in oversight of toxic event.

A good calibration of the system will allow to obtain the most reliable response.

\subsection{Estimation of the partial wastewater flow toxicity on the total stream}

Another issue to be explored is the possibility of determining toxicity level downstream from measurement point - with a focus on WWTP inflow. A possible scenario is the dilution of the toxic substance on the way to the treatment plant. Attempts shall be made to 
assess whether it is possible to unambiguously estimate the toxicity after combining sewage streams. Next, examination of the factors on which it is dependent should be carried out. This constitutes another challenge which can significantly affect the reliability of the system.

\section{Related works}

The scientific community is aware of the problem, which is unforeseen discharge of toxic substances into the sewerage system $[1,2,4,9]$. However, most of the scientific work focuses on the detection of inhibition only at the waste water treatment plant $[2,5,7,8]$. As a result, processes for wastewater treatment are not protected and corrective actions cannot be undertaken. The concept of the EWS presented in this paper is convergent with the attitude presented by G.Black et al. [3]. Available analyses and research provide valuable information required for development and design of the device [1-5, 7-10]. Despite understanding the essence of the problem, EWS for toxic upsets prevention is not commonly used in sewage network. This constitutes the need of development and implementation of such technology with easy to use and reliable OUR measurements. Further work and development of the subject are advised.

\section{References}

1. K. Jönsson, C. Grunditz, G. Dalhammar, JLC. Jansen, Water Research 34 (2000)

2. P. Norman, P. Whalen, A new method for upset prediction: ATP-based biomonitoring and statistical process analysis at two refinery wastewater plants, Proceedings of the Water Environment Federation, WEFTEC 2009: Session 31 through Session 40, pp. 2506-2525(20) (2009)

3. G. Black, Pollution prevention in wastewater networks: Development of biological early warning device, (Cranfield University, 2016)

4. A. Shaw, N. Love, E. Roehl, Feasibility testing of support systems to prevent upsets - WERF Final Report, United States of America, IWA Publishing, ISBN: 1-84339795-1 (2009)

5. W. Bourgeois, J. Burgess, R. Stuetz, Journal of Chemical Technology and Biotechnology 76 (2001)

6. M. Głodniok, K. Korczak, D. Zdebik, Prace Naukowe GIG. Górnictwo i Środowisko, $1(2010)$

7. J. Gorska-Surmacz, K. Gernaey, C. Demuynck, P. Vanrolleghem, W. Vestraete, Water Research 30 (1996)

8. S. Hong, I. Choi, BJ. Lim, H. Kim, 12 (2012)

9. A. Shaw, A. Fairey, J. Earle, N. Love, E. Roehl, R. Daamen, G. Olsson, J. Watts, Online Instrumentation to Protect Wastewater Facilities from Toxic Chemicals, Proceedings of the Water Environment Federation, WEFTEC 2006: Session 51 through Session 60, pp. 4553-4562(10) (2006)

10. Y. Xiao, C. De Araujo, CC. Sze, DC. Stuckey, Singapore, Journal of Hazardous Materials 286 (2015)

11. J. Alleman, K. Preston, The biology of nitrifying bacteria, Second annual workshop on commercial aquaculture using water recirculating systems, (Purdue University, 1991) 